6. World Health Organization. Lassa fever-Germany. Disease outbreak news, 23 March 2016 [cited 21 Aug 2017].

http://www.who.int/csr/don/23-march-2016-lassa-fever-germany/en/

7. World Health Organization. Lassa fever-Togo. Disease outbreak news, 23 March 2016 [cited 21 Aug 2017]. http://www.who.int/csr/ don/23-march-2016-lassa-fever-togo/en/

8. Raabe VN, Kann G, Ribner BS, Morales A, Varkey JB, Mehta AK, et al.; Emory Serious Communicable Diseases Unit. Favipiravir and ribavirin treatment of epidemiologically linked cases of Lassa fever. Clin Infect Dis. 2017;65:855-9.

9. Lehmann C, Kochanek M, Abdulla D, Becker S, Boll B, Bunte A, et al. Control measures following a case of imported Lassa fever from Togo, North Rhine Westphalia, Germany, 2016. Euro Surveill. 2017;22:pii:17-00088.

10. Ehlkes L, George M, Samosny G, Burckhardt F, Vogt M, Bent S, et al. Management of a Lassa fever outbreak, Rhineland-Palatinate, Germany, 2016. Euro Surveill. 2017;22:pii:16-00728.

Address for correspondence: Stephan Günther, Department of Virology, Bernhard-Nocht-Institute for Tropical Medicine, Bernhard-Nocht-Str. 74, 20359 Hamburg, Germany; email: guenther@bni.uni-hamburg.de

\section{Evidence for Previously Unidentified Sexual Transmission of Protozoan Parasites}

\section{Clara Crespillo-Andujar, ${ }^{1}$ Marta Díaz-Menéndez, ${ }^{1}$ Marta Mora-Rillo}

Author affiliations: National Referral Unit for Tropical and Travel Medicine, Hospital Universitario la Paz-Carlos III, Madrid, Spain

(C. Crespillo-Andujar, M. Díaz-Menéndez); Hospital Universitario la Paz-Carlos III, Madrid (M. Mora-Rillo)

DOI: https://doi.org/10.3201/eid2403.171838

Knowing the mode of transmission of a disease can affect its control and prevention. Here, we identify 5 protozoan parasites with demonstrated presence in seminal fluid, only 1 of which has been identified as a sexually transmitted disease among humans.

A recent publication by Salam and Horby (1) identified at least 27 viruses present in human semen, some potentially transmissible through sexual contact. Trichomonas vaginalis is a protozoan parasite recognized as sexually transmissible among humans (2). Similar to that which

\footnotetext{
${ }^{1}$ These first authors contributed equally to this article.
}

occurs with viruses, parasites could reach seminal fluid by passing from the bloodstream to the male genital tract or by directly infecting reproductive organs. In this context, more parasitic infections might also be transmitted sexually. Considering that parasitic diseases represent one of the most common infections worldwide, mainly in developing countries, sexual transmission of parasitic diseases could represent a major global problem in terms of public health.

To investigate whether parasites could enlarge the broad list of potential sexually transmitted infections (STIs), we conducted an online search on November 3, 2017, by using PubMed (https://www.ncbi.nlm.nih.gov/ pubmed/), EMBASE (https://www.elsevier.com/solutions/ embase-biomedical-research), and the Cochrane Library (http://www.cochranelibrary.com/) with no language restrictions. We used the terms "parasites OR parasitic disease" and "semen OR seminal plasma." We also made a manual search of the references of selected reports. Two reviewers independently screened the 512 returned results of titles, abstracts, and full text in selected articles.

Our search resulted in 5 parasite species with demonstrated presence in seminal fluid of humans: Entamoeba hystolytica (3), Schistosoma haematobium (4), Trichomonas vaginalis (2), Trypanosoma cruzi (5), and Toxoplasma gondii; the latter has been documented as sexually transmitted among animals, but not humans (6) (Table). E. hystolytica is a worldwide anaerobic protozoan; its prevalence increases disproportionately in areas of poor sanitation in low-income countries. E. hystolytica has been identified in the testicles, epididymis, and seminal fluid $(3,7)$, can reportedly cause infertility as a result of reproductive organ damage $(8)$, and is transmitted by sexual contact (both oral-anal and oral-genital sexual practices) (7).

Urogenital schistosomiasis caused by $S$. haematobium infection affects male and female children and adults mainly in Africa, the Middle East, and Corsica, France. After the larval $S$. haematobium cercarias penetrate intact skin from contaminated fresh water, they migrate and mature into adult worms, predominantly in the venous plexus of the bladder. These worms can then travel to the seminal vesicles and prostate, causing local pathology (9). S. haematobium eggs have been found in up to $43 \%$ of 44 semen samples and in $33.3 \%$ of cervix biopsies obtained from 36 women from endemic area populations $(4,10)$; nevertheless, sexual transmission has not been reported.

T. vaginalis protozoa are the most common nonviral STI in the world, and incidence is increasing (11). The genital tract of humans is the natural habitat for this parasite, which can cause urogenital tract infection. $T$. vaginalis has been identified in seminal fluid and has been related to decreased sperm quality $(2,8)$.

Chagas disease is caused by T. cruzi protozoa and affects nearly 6 million persons in Latin America countries. 
Table. Results of literature search for reports of parasites found in semen samples

\begin{tabular}{|c|c|c|c|c|}
\hline Parasite (reference) & $\begin{array}{l}\text { Method for parasite } \\
\text { identification }\end{array}$ & Type of study & $\begin{array}{c}\text { Evidence of sexual } \\
\text { transmission }\end{array}$ & $\begin{array}{l}\text { Evidence of causing } \\
\text { infertility }\end{array}$ \\
\hline Entamoeba hystolytica (2) & Microscopy & Case report & In humans & In humans \\
\hline Schistosoma haematobium (3) & Microscopy & Cohort study & No evidence & In humans \\
\hline Trichomonas vaginalis (4) & PCR & Cohort study & In humans & In humans \\
\hline Trypanosoma cruzi (5) & PCR & Cohort study & Experimental mouse model & In animals \\
\hline Toxoplasma gondii (6) & Microscopy & Cohort study & Experimental sheep model & In humans \\
\hline
\end{tabular}

Parasitic involvement of the male genital tract, alteration in semen characteristics (7), and the presence of the parasite's DNA in semen have recently been identified in chronically infected patients (5). Furthermore, an experimental mouse model has demonstrated infection through intravaginal infusion of semen from infected humans, posing the possibility of sexual transmission among humans (5).

Toxoplasmosis is a protozoan disease caused by T. gondii infection, with a worldwide prevalence from $20 \%$ to $80 \%$. $T$. gondii has been found in the semen of infected men (6), and infection has been related to a decrease in semen quality (8). An experimental sheep model demonstrated infection after vaginal infusion of vegetative cysts of $T$. gondii (7).

Despite evidence of the presence of parasites in semen, the specific mechanism by which the parasite reaches the semen has not been clearly elucidated. The male genital tract can be invaded through a connection from the urethra to the testis or epididymis (T. vaginalis, S. haematobium), invasion from an adjacent structure (E. hystolytica), or as a result of a disseminated infection (T. cruzi, T. gondii) (7).

Other parasites, such as Plasmodium spp. and Trypanosoma brucei, can affect human spermatogenesis and impair fertility $(7,8)$. Leishmania spp. have been detected in the testes in autopsies of patients who died of visceral leishmaniasis, and infection with these species has induced infertility (8). Although the presence of the Leishmania, T. brucei, and Plasmodium spp. in the male genital tract have been demonstrated, they have not been detected in human semen (7).

According to our review, it might be crucial to consider the sexual route of infection among parasitic diseases with seminal presence in addition to viral diseases previously identified (1). Infertility might be a consequence of parasitic infection regardless of its presence in seminal fluid (8).

These parasitic infections primarily affect vulnerable populations in developing countries. Many of these diseases are classified as neglected tropical diseases because of the scarcity of resources for their study; thus, potential sexual transmission of them is underresearched. The lack of available scientific information about the role of parasites in genital fluids leaves room for confusion about the relative importance of sexual activity as a route of transmission. Further studies are needed to implement better public health strategies.

Funding was provided by ISCIII, project "RD16/0027/0002" (Red de Enfermedades Tropicales, Subprograma RETICS del Plan Estatal de I+D+I 2013-2016) and by FEDER.

\section{About the Authors}

Dr. Crespillo-Andujar and Dr. Díaz-Menéndez are attending physicians at the Tropical Medicine and International Travel Unit, Department of Internal Medicine, Hospital Universitario la Paz-Carlos III, Madrid, Spain. Their main research interests are tropical and travel medicine and infectious diseases.

\section{References}

1. Salam AP, Horby PW. The breadth of viruses in human semen. Emerg Infect Dis. 2017;23:1922-4. http://dx.doi.org/10.3201/ eid2311.171049

2. Ozdemir E, Keleştemur N, Kaplan M. Trichomonas vaginalis as a rare cause of male factor infertility at a hospital in East Anatolia. Andrologia. 2011;43:283-5. http://dx.doi.org/10.1111/ j.1439-0272.2010.01119.x

3. Hines LE. Entamoeba histolytica in seminal fluid in a case of amoebic dysentery. JAMA. 1923;81:274-5. http://dx.doi.org/ 10.1001/jama.1923.02650040014003

4. Leutscher P, Ramarokoto CE, Reimert C, Feldmeier H, et al. Community-based study of genital schistosomiasis in men from Madagascar. Lancet. 2000; 8;355(9198):117-8. http://dx.doi.org/ 10.1016/S0140-6736(99)04856-4

5. Araujo PF, Almeida AB, Pimentel CF, Silva AR, Sousa A, Valente SA, et al. Sexual transmission of American trypanosomiasis in humans: a new potential pandemic route for Chagas parasites. Mem Inst Oswaldo Cruz. 2017;112:437-46. http://dx.doi.org/10.1590/0074-02760160538

6. Disko R, Braveny I, Vogel P. Studies on the occurrence of Toxoplasma gondii in the human ejaculate [in German]. Z Tropenmed Parasitol. 1971;22:391-6.

7. Martinez-García F, Regadera J, Mayer R, et al. Protozoan infections in the male genital tract. J Urol. 1996;156;340-9. PubMed https://doi.org/10.1016/S0022-5347(01)65846-4

8. Shiadeh MN, Niyyati M, Fallahi S, Rostami A. Human parasitic protozoan infection to infertility: a systematic review. Parasitol Res. 2016;115:469-77. http://dx.doi.org/10.1007/ s00436-015-4827-y

9. Centers for Disease Control and Prevention. Laboratory identification of parasitic diseases of public health concern. Schistosomiasis infection. Dec 18, 2017 [cited 2018 Jan 15] https://www.cdc.gov/dpdx/schistosomiasis/index.html

10. Leutscher P, Ravaoalimalala VE, Raharisolo C, et al. Clinical findings in female genital schistosomiasis in Madagascar. Trop Med Int Health 1997; 3: 327-32. https://doi.org/10.1046/ j.1365-3156.1998.00230.x

11. World Health Organization. Global incidence and prevalence of selected curable sexually transmitted infections-2008. Geneva: The Organization; 2012 [cited 2017 Nov 6]. http://www.who.int/reproductivehealth/publications/rtis/ stisestimates/en/

Address for correspondence: Marta Díaz-Menéndez, Tropical Medicine and International Travel, Hospital Universitario la Paz-Carlos III,

Madrid, Spain; email: marta.diazmenendez@gmail.com 